\title{
PENGELOLAAN LINGKUNGAN DENGAN CARA MEMANFAATKAN FLY ASH BATUBARA SEBAGAI BAHAN BAKU MEMBRAN SILIKA DALAM UPAYA MEMINIMALISIR LIMBAH B3 DI PT SEMEN BATURAJA OKU
}

\author{
${ }^{1}$ Lety Trisnaliani, ${ }^{2}$ Indah Purnamasari, ${ }^{3}$ Ahmad Zikri dan ${ }^{4}$ Selastia Yuliati \\ ${ }^{1}$ Program Studi D-IV Teknik Energi Jurusan Teknik Kimia Politeknik Negeri Sriwijaya \\ E-mail : lety.trisnaliani@polsri.ac.id \\ ${ }^{2}$ Program Studi D-III Teknik Kimia Teknik Energi Jurusan Teknik Kimia Politeknik Negeri Sriwijaya \\ E-mail : indah_chemistry@yahoo.com \\ ${ }^{3}$ Program Studi D-IV Teknik Energi Jurusan Teknik Kimia Politeknik Negeri Sriwijaya \\ E-mail : zikri90@gmail.com \\ ${ }^{4}$ Program Studi D-III Teknik Kimia Jurusan Teknik Kimia Politeknik Negeri Sriwijaya \\ E-mail : selastiayuliati@yahoo.com
}

\begin{abstract}
Abtract
The target of community service assignments in 2018 is productive communities that need development in the field of environmental management, namely employees of the Quality Control Laboratory of PT. Semen Baturaja OKU. Coal ash is a waste unlike gas from combustion, because it is a solid material that is not easily dissolved and is not volatile so it will be more troublesome in handling. If the amount is large and is not handled properly, then the coal ash can pollute the environment especially caused by fly ash and can be sucked by humans and animals can also affect the condition of the surrounding water and soil so that it can kill the plants. The chemical composition of Fly ash is silica, alumina and iron with little calcium, magnesium, sulfate, and other components. Currently coal fly ash is used in cement plants as a mixture of concrete makers. Because of the smoothness and round shape of the granules, the use of fly ash on the concrete mixture can increase the slack on the concrete mixture. The advantages of using fly ash include increasing the strength of concrete, filling the pores in the concrete so that the porosity of the concrete becomes low, while increasing the density of concrete so that it can increase the tightness of concrete to water. The coal fly ash waste that accumulates also occurs in the industry of PT Semen Baturaja Ogan Komering Ulu. PT. Semen Baturaja is one of the largest cement industries in Sumatra that produces PCC (Portland Composite Cement). PCC type cement is cement made by utilizing inorganic additives such as fly ash and trass. Aside from being an additional material for cement, fly ash can also be used as a raw material for making silica membranes which serves to reduce metal content in acid mine drainage. So that the author wishes to socialize the employees and employees of PT Semen Baturaja especially in the BTA II Quality Control laboratory division to disseminate knowledge about the benefits of coal fly ash as raw material for silica membranes in minimizing $B 3$ waste so that environmental management with a friendly environment will achieved.
\end{abstract}

Keywords : coal fly ash, environmental management, B3 waste, metal content

\section{Pendahuluan}

Peningkatan taraf hidup masyarakat dan kesejahteraan secara umum harus terus dilakukan dengan melakukan pembangunan yang berkesinambungan. Perkembangan teknologi industri yang pesat akan memberikan dampak tidak langsung terhadap lingkungan sekitarnya. Seiring pembangunan industri di setiap sektor, permasalahan limbah produk pasti akan didapat sebagai efek samping suatu proses. Abu batubara merupakan limbah bahan padat yang tidak mudah larut dan tidak mudah menguap sehingga akan lebih merepotkan dalam proses penanganannya. Dalam jumlah yang banyak maka abu batubara tersebut dapat mengotori lingkungan terutama yang disebabkan oleh abu yang beterbangan di udara (fly ash). Abu juga dapat terhisap oleh manusia dan hewan juga dapat mempengaruhi kondisi air dan tanah di sekitarnya sehingga dapat mematikan 
tanaman. Komposisi kimia dari fly ash yaitu silika, alumina dan besi dengan sedikit kalsium, magnesium, sulfat, dan komponen yang lain. Saat ini abu terbang batubara digunakan dalam pabrik semen sebagai salah satu bahan campuran pembuat beton. Karena kehalusan dan bentuk bulat butirannya maka pemakaian abu terbang pada adukan beton dapat menambah kelecakan pada adukan beton. Keuntungan penggunaan fly ash antara lain memberikan peningkatan kekuatan beton, mengisi pori-pori pada beton sehingga porositas beton menjadi rendah, serata meningkatkan kerapatan beton sehinggga dapat meningkatkan kekedapan beton terhadap air.

Limbah fly ash batubara yang menumpuk juga terjadi di PT Semen Baturaja Ogan Komering Ulu. Selain sebagai bahan tambahan semen, fly ash juga bisa dimanfaatkan sebagai bahan baku pembuatan membran silika yang berfungsi menurunkan kadar logam pada air asam tambang. Sehingga penulis berkeinginan melakukan sosialisasi terhadap karyawan dan karyawati PT Semen Baturaja khususnya pada divisi laboratorium Quality Control BTA II untuk menyebarluaskan ilmu pengetahuan mengenai manfaat fly ash batubara dalam meminimalisir limbah B3 sehingga pengelolaan lingkungan dengan konsep ramah lingkungan (friendly environment) akan tercapai. Salah satu program lingkungan dari PT Semen Baturaja adalah juga memanfaatkan fly ash batubara sebagai kerja program lingkungan hidup yang berhubungan dengan kegiatan operasional Perseroan.

\section{Target dan Luaran}

Dalam kehidupan sehari-hari kita sering mendengar kata pencemaran. Salah satu pencemaran yang paling berbahaya dan memberikan dampak yang cukup besar adalah pencemaran udara. Pencemaran udara sendiri mengandung pengertian masuk atau dimasukkannya makhluk hidup, zat, atau komponen lain ke dalam udara dari kegiatan manusia atau proses alam sehingga menurunkan kualitas udara tersebut ke titik tertentu yang menyebabkan udara menjadi kurang/tidak berfungsi lagi sesuai dengan peruntukkannya. Pada dasarnya pencemaran itu berbahaya bagi kehidupan, tetapi pencemaran udara menjadi salah satu pencemaran yang dikategorikan sebagai pencemaran yang sangat berbahaya. Hal ini dikarenakan partikel polutan dari pencemaran ini berukuran sangat kecil sehingga tidak disadari oleh manusia. Sumber pencemar dalam pencemaran udara tidak hanya berasal dari aktivitas manusia tetapi juga oleh sumber pencemar yang datangnya akibat peristiwa alamiah seperti gunung meletus, bencana alam, dan lain-lain.

Partikulat termasuk dalam salah satu polutan pencemaran udara. Partikel-partikel tersebut sangat merugikan kesehatan manusia. Pada umumnya udara yang telah tercemar oleh partikel dapat menimbulkan berbagai macam penyakit saluran pernapasan atau pneumoconiosis.

Fly Ash merupakan salah satu jenis partikulat yang dapat diklasifikasikan dalam debu. Hal ini karena biasanya Fly Ash dipengaruhi oleh gaya gravitasi bumi. Abu terbang (fly ash) sebagai limbah berbahan bakar batu bara dikategorikan oleh Bapedal sebagai limbah berbahaya (B3). Jika limbah abu ini tidak dimanfaatkan akan menjadi masalah pencemaran lingkungan, yang mana dampak dari pencemaran akibat abu terbang (fly ash) sangat berbahaya baik bagi lingkungan maupun kesehatan. Oleh karena itu, penulis berkeinginan menyebarluaskan ilmu pengetahuan agar fly ash ini bisa bermanfaat sehingga dapat meminimalisir limbah B3 yang ada di sekitar lingkungan PT Semen Baturaja. Para karyawan dan karyawati PT Semen Baturaja merupakan ujung tombak keberhasilan dari suatu perusahaan semen tersebut dalam mengelola manajemen aset dan produk semen yang dihasilkan. Produk semen PT Semen Baturaja sudah menggunakan fly ash sebagai bahan campuran semen yang mereka produksi sekarang ini. Namun selain sebagai bahan campuran semen, fly ash batubara diketahui juga dapat bermanfaat sebagai bahan baku pembuatan membran untuk membantu upaya pengelolaan lingkungan di PT Semen Baturaja. Pada pengabdian yang dilakukan di PT Semen Baturaja, penulis mengajak karyawan dan karyawati khususnya divisi Laboratorium Quality Control BTA II menjadi mitra dalam kegiatan pengabdian masyarakat dengan cara menyebarluaskan ilmu pengetahuan pemanfaatan dari fly ash sebagai membran yang berfungsi menurunkan kadar logam $\mathrm{Mn}$ dalam pengelolaan lingkungan pada air asam hasil tambang. Adapun keluaran yang 
diharapkan adalah agar para mitra tersebut dapat memanfaatkan ilmu pengetahuan tersebut untuk dikembangkan di laboratorium quality control BTA II dan penulisan artikel dari penyebaran ilmu pengetahuan ini bisa berupa jurnal pengabdian dan bahan ajar.

\section{Metode Pelaporan}

Kegiatan pengabdian kepada masyarakat ini akan dilakukan dengan cara ceramah (presentasi dengan power point) dan berdiskusi secara interaktif sehingga para mitra benar - benar dapat merasakan manfaat yang diperoleh dari hasil kegiatan ini. Diharapkan dengan adanya kegiatan pengabdian ini munculnya inovasi - inovasi baru dari para karyawan dan karyawati tersebut untuk mengembangkan ilmu pengetahuan menjadi suatu produk yang layak pakai dan memiliki nilai komersil yang bermanfaat dalam pengelolaan lingkungan sekitar PT Semen Baturaja.

Kegiatan ini dilakukan dengan presentasi dan memberikan prosedur kerja pembuatan membran silika berbahan baku fly ash dengan memberikan contoh sampel membran yang telah dibuat sebelumnya sehingga mitra dapat melihat bentuk produk yang dapat mereka kembangkan. Selain pembuatan membran dari fly ash, mitra juga diharapkan dapat membuat inovasi baru lainnya dalam pengembangan pemanfaatan fly ash batubara.

\section{Hasil Pelaksanaan Program}

Berangkat dari kenyataan banyaknya kasus pencemaran lingkungan dengan mengingat kecendrungan melimpahnya limbah batubara (fly ash) yang belum optimal dimanfaatkan sehingga menjadi problem lingkungan yang cukup serius ke depannya. Pemanfaatan limbah fly ash akan sangat membantu program pemerintah dalam mengatasi pencemaran lingkungan. Metode pelaksanaan kegiatan pengabdian ini adalah dengan pola eksplorasi pengetahuan, kesadaran terhadap lingkungan, dan keterampilan serta bentuk pendekatan yang dilakukan untuk meningkatkan motivasi mitra agar mau dan mampu untuk mengembangkan inovasi dari penelitian yang sudah ada yaitu dengan melakukan sosialisasi tentang pentingnya memanfaatkan fly ash batubara sebagai bahan baku membran silika.
Dengan hasil ini, maka metode yang dilaksanakan dalam kegiatan pengabdian ini layak untuk dilanjutkan untuk mencapai target diadakannya kegiatan ini. Masyarakat produktif yang menjadi mitra kali ini adalah para karyawan yang memang notabene berkecimpung dalam divisi laboratorium penelitian, sehingga hal ini memudahkan nara sumber dalam mentransfer ilmu pengetahuan mengenai pemanfaatan abu terbang (fly ash). Kegiatan pengelolaan lingkungan sesungguhnya telah menjadi salah satu program yang dihandalkan oleh divisi operasional PT Semen Baturaja dan kegiatan diseminasi ilmu pengetahuan mengenai pengelolaan lingkungan di anggap sudah sejalan dan wajar untuk dijalankan dalam mendukung segala program yang bersifat ramah lingkungan (friendly environment).

Dari kegiatan yang sudah dilakukan terlihat bahwa peserta program pengabdian masyarakat ini sangatlah antusias dalam memberikan pertanyaan dan memiliki kemauan untuk menyebarluaskan ilmu pengetahuan cara memanfaatkan fly ash batubara sebagai bahan baku membran silika.

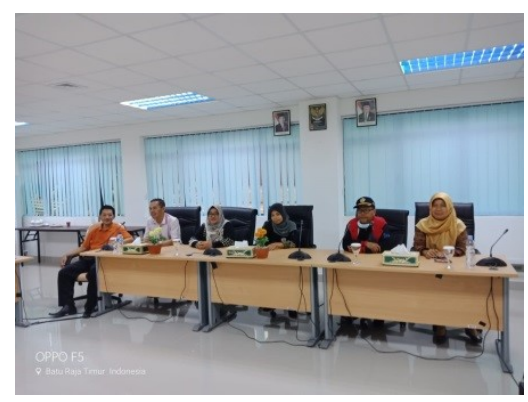

$1 a$.

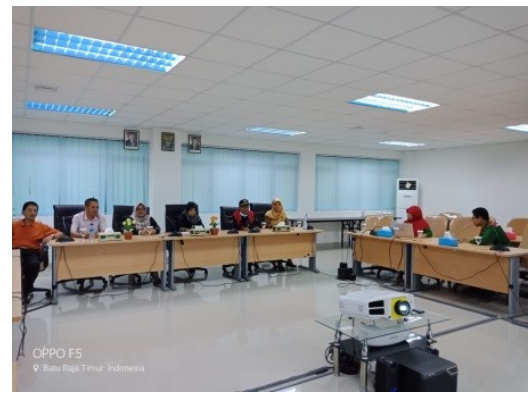

1 b.

Gambar 1a dan 1b. Presentasi Kegiatan Pengabdian 


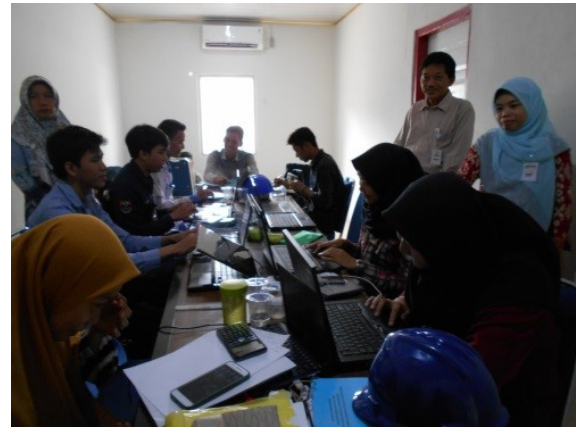

2 a.

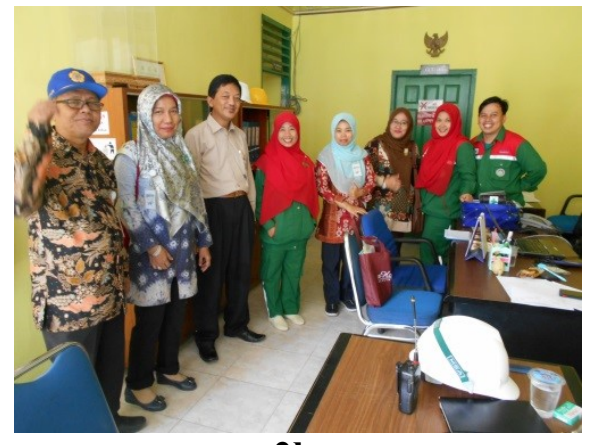

2b.

Gambar 2a dan 2b. Peserta Kegiatan Pengabdian

\section{Kesimpulan}

Kesimpulan dan saran yang bisa didapatkan dari kegiatan Pengabdian Kepada Masyarakat adalah sebagai berikut :

1. Pemberian informasi pemanfaatan fly ash batubara sebagai bahan baku pembuatan silika penting dilakukan untuk menumbuhkan kepedulian masyarakat produktif sebagai mitra pada masalah krisis energi dan lingkungan, serta memotivasi peserta untuk berperan serta dalam mendukung program pengelolaan lingkungan bersih.

2. Informasi pemanfaatan fly ash batubara sebagai bahan baku pembuatan silika yang diberikan telah memberikan pengetahuan dan ketrampilan kepada para peserta untuk membuat inovasi - inovasi yang lebih baik dan terbarukan.

3. Peserta program sebagai mitra bisa menyebarkan informasi kepada masyarakat produktif lainnya.

\section{Daftar Pustaka}

Afrianti,R., Fitria,D., dan Sari,P.R.. 2010. Pemanfaatan Fly Ash Batubara sebagai Adsorber dalam Penyisihan Chemical
Oxygen Demand (COD) dari Limbah Cair Domestik. Jurnal Teknik Lingkungan Universitas Andalas. 1(33), 81-93.

Mardiono. 2011. Pengaruh Pemanfaatan Abu Terbang (Fly Ash) dalam Beton Mutu Tinggi. Universitas Gunadarma, Jakarta.

Suprihatin,E., Zaharani,T.A., dan Dewi,T.K.. 2012. Pembuatan Membran Silika dari Fly Ash dan Aplikasinya untuk Menurunkan Kadar COD dan BOD Limbah Cair Kelapa Sawit. Jurnal Kimia Universitas Tanjungpura. 4(3), 48-53. 